\title{
Body Composition and Bone Mineral Quality in Phenylketonuria: Influence of Pubertal Development
}

Tummolo $A^{1 *}$, Arico $M^{2}$, Pesce $S^{1}$, Fantasia $M^{3}$, Paterno G ${ }^{1}$, Melpignano $L^{4}$, De Giovanni $D^{1}$ and Faienza $\mathbf{M F}^{3}$

${ }^{1}$ Department of Metabolic Diseases, Azienda Ospedaliero Universitaria Consorziale, Italy

${ }^{2}$ Strategic Control, Azienda Ospedaliero Universitaria Consorziale, Bari, Italy

${ }^{3}$ Department of Biomedical Sciences and Human Oncology, University “A. Moro”, Italy

${ }^{4}$ Medical Direction, Children's Hospital Giovanni XXIII, Bari, Italy

*Corresponding author: Albina Tummolo, Metabolic Diseases and Clinical Genetics and Diabetology, Children's Hospital Giovanni XXIII, Azienda Ospedaliero-Universitaria Consorziale, Via Amendola 207, 70126, Bari, Italy

Received: March 03, 2021; Accepted: April 03, 2021; Published: April 10, 2021

\begin{abstract}
Background/Objectives: Early diagnosis and a low-Phe diet significantly improved prognosis of PKU patients whose management is now-a-day mostly focused on preventing nutritional imbalances and resulting comorbidities. Puberty is a turning point for the risk to develop overweight and bone quality impairment. The present study aims to evaluate body composition and bone quality in prepubertal and pubertal PKU patients.
\end{abstract}

Subjects/Methods: This is an observational, prospective study on an historical cohort of patients with PKU aged between 4.1 and 18 years, with early diagnosis and continuous protein-restrictive diet treatment. Bioimpedance, weight measurements, height, body mass index calculation, and quantitative ultrasound were collected. Sexual maturity was evaluated by using the Tanner staging.

Results: Thirty PKU patients (14 prepubertal, 16 pubertal) were included in the study. Mean BMI was within the normal range in both groups, although fat content was higher in prepubertal, whereas lean mass was higher in the pubertal group who had also a higher total protein content. Among QUS parameters, bone quality index and broadband ultrasound were lower in prepubertal children than in adolescents, with a Z-score BQI within the osteopenia range in both of them.

Conclusions: Pubertal patients with PKU develop a higher lean mass and protein content. If on one hand the high non-Phe protein intake in the pubertal period may promote increase in bone mineral quality, on the other hand the higher protein retention, typical of this period, may increase the risk for hyperinsulinism and glucose intolerance in later life. Adjusting dietary management by modulating total protein intake in the peripubertal period could result in better management of PKU patients.

Keywords: Phenylketonuria; Body composition; Bioelectric impedance; Quantitative ultrasound; Puberty

\section{Abbreviations}

PKU: Phenylketonuria; BIA: Bioelectric Impedance; QUS: Quantitative Ultrasound; BMI: Body Mass Index; BUA: Broadband Ultrasound Attenuation; SOS: Speed of Sound

\section{Introduction}

Phenylketonuria (PKU) (OMIM: 261600) is an inborn error of metabolism caused by a deficient activity of Phenylalanine Hydroxylase (PAH), needed to convert Phenylalanine (Phe) into tyrosine [1]. Early diagnosis through neonatal screening and a low-Phe diet significantly improve prognosis, resulting in patients reaching adulthood with normal mental development and a better quality of life [2-4]. Over the years, the main target of PKU patient management progressively shifted from preventing early death and irreversible intellectual disability to preventing nutritional imbalances and resulting comorbidities [5].

Overweight and obesity in children with PKU result from unbalanced diet, low calcium intake and a sedentary life [6,7]. Relevant dietary factors include the quality and quantity of tolerated protein, and frequent excess of non-protein caloric intake [8,9]. In turn, such protein-restricted regimens may result into short and long-term nutritional risks [10]. Based on that, monitoring the patient trend in nutritional status by a more comprehensive and systemic nutritional assessment is warranted [11]. Assessing Body Composition (BC) is mandatory to increase accuracy of the nutritional status evaluation [12]. In addition to the Body Mass Index (BMI), Bioelectric Impedance (BIA) is another useful tool to assess the real tissue mass [12,13]. In particular, BIA is a 2-compartment method for body composition assessment, based on impedance measurements of biological tissues. The measured impedance is proportional to the Total Volume of Body Water (TBW). In the presence of a constant TBW to lean mass (FFM) ratio, the impedance can be converted to FFM. Fat Mass (FM) can be determined by calculating the difference between total body weight and FFM [14].

During adolescence, hormonal fluctuations cause a genderspecific increase in lean mass, fat mass and bone mass, making adolescents prone to develop insulin resistance, which in turn appears to play a reciprocal role in the changes observed in body composition [15]. 
A high-protein diet may lead to a further lean body mass gain, [16]; therefore, due to the high, Phefree, protein intake, PKU patients, especially in adolescence, may be more exposed to alterations in body composition [10].

An additional concern is related to bone health, which is impaired in PKU subjects, leading to stunted growth and risk of fractures [1719]. Thus, Bone Mineral Density (BMD) assessment is also part of the routine follow-up assessment of PKU patients [20,21]. Dual Energy X-Ray Absorptiometry (DXA) of the lumbar spine and hip is usually preferred for evaluating $\mathrm{BMD}$, as it provides the most reliable measurement for predicting fracture risk and monitoring treatment. However, studies conducted so far using DXA to assess BMD have produced conflicting data in PKU subjects, and the data refer mainly to adults [22,23]. DXA provides two-dimensional (areal) values for BMD, does not distinguish cortical from trabecular bone and should be adjusted for height and weight when used in children and adolescents. Quantitative Ultrasound (QUS) is an easy, inexpensive and radiation-free alternative diagnostic tool to assess bone quality and fracture rate the in children and adolescents with bone and mineral disorders [24-27].

QUS, measuring the attenuation and velocity of ultrasound waves passing through the calcaneus bone, is now part of bone health assessment [28]. It has been reported that Broadband Ultrasound Attenuation (BUA) and Speed of Sound (SOS) exhibit distinct structural properties of bone, with BUA more related to structural parameters such as connectivity and porosity of the skeleton, and SOS more influenced by bone mineral mass and elasticity [29].

Given the lack of literature data on nutritional status and bone health in the peripubertal period, the present study aims to investigate the changes of body composition and bone quality in prepubertal and pubertal PKU patients, also exploring some predisposing factors to later life comorbidities.

\section{Materials and Methods}

\section{Subjects}

We performed an observational, prospective study on an historical cohort of patients with PKU (13 males and 17 females, median age 10.8 years (range 4.1-18) diagnosed by neonatal screening and confirmed by molecular analysis. Patients with PKUindependent, concomitant conditions affecting bone mineralization and/or nutritional status and/or pubertal spurt timing (precocious or delayed puberty) were excluded. Type of PKU was assigned on the basis of neonatal pre-diet Phe levels, according to the PKU European Guidelines [11]. Written informed consent was obtained from the parents. This study was approved by local IRB. All the procedures used were in accordance with the guidelines of the Declaration of Helsinki on Human Experimentation.

\section{Anthropometry}

Patients were weighed and measured in minimal clothing, by the same balance and altimeter. Body mass index (BMI) was calculated as the weight/height ${ }^{2}$ ratio. Normal values of BMI Z-score ranged between +1.0 and -1.0 , using the World Health Organization (WHO) charts [30]. Tanner stage (prepubertal, Tanner 1; pubertal, Tanner 2 to 5), was determined by physical examination [31].

\section{Dietary intake and biochemical measurements}

All patients were treated with a protein-restrictive diet supplemented with amino acid mixtures. The same metabolic dietitian, using the Winfood Pro software (version 3.0.0, 2011, Medimatica Srl, Teramo, Italy) analyzed dietary data from each patient. Dietary protein intake, expressed in grams per kilograms per day, was compared with $\mathrm{FAO} / \mathrm{WHO} / \mathrm{UNU}$ recommended safe levels [32]. Energy intake was expressed as $\mathrm{kcal} /$ day and compared with $\mathrm{FAO} / \mathrm{WHO} / \mathrm{UNU} 1985$ requirements. All patients were monitored weekly by Phe dosage on blood spot, and dietary compliance was defined as poor if mean DBS Phe level was higher than the target level, or good if mean dried blood spot Phe level was within the target Phe level, according with PKU European Guidelines [11]. Serum samples were assayed for vitamin D status (total 25(OH)D concentration), lipid panel (Total Cholesterol (TC), Triglycerides (TG), High-Density Lipoprotein Cholesterol (HDL-C), Low-Density Lipoprotein Cholesterol (LDL-C), and glucose status (fasting glucose concentration) for all participants. Risk of dyslipidemia was assessed according to reference cut-off values for fasting lipids in children [33]. Vitamin D status was also evaluated according to the current standard for Italian target population [34,35].

\section{Body composition}

A trained study assistant performed all BIA measurements. A multi-frequency $(20 \mathrm{kHz}$ and $100 \mathrm{kHz}$ ) BIA device using eight-point tactile electrode system (Inbody 230, Biospace Corp., Seoul, Korea), referred to as BIA8MF [36] was used. After the sex, age and height information introduction into the BIA8MF, subjects were asked to stand in a stable position with bare feet. Their toes and heels had to be placed in contact with the anterior and posterior electrodes of the weighting platform, respectively. The BIA8MF produces 10 impedance values to measure five segments of the body: right leg, left leg, right arm, left arm and the trunk. The measurements began when both hands grasped the grips, and feet were in the right position. Body composition parameters, calculated by manufacturer software (Lookin'Body 120, Biospace Corp., Seoul, Korea) were: Fat Mass (FM) (Kg), Percentage of Body Fat (PBF), Total Body Water (TBW) (Kg), Waist-Hip Ratio (WHR) and Lean Body Mass (LBM) (Kg).

\section{Quantitative Ultrasound Scan (QUS)}

The QUS (SONOST 3000) measurement score of the calcaneus region was used to calculate the bone mineral density (BMD) status according to the WHO criteria (normal, osteopenia and osteoporosis) [37]. The machine was calibrated daily according to the manufacturer's instructions.

The outputs included the Bone Quality Index (BQI), the Broadband Ultrasound Attenuation (BUA, measured in $\mathrm{dB} / \mathrm{MHz}$ ), the speed of sound (SOS, measured in $\mathrm{m} / \mathrm{s}$ ). BUA reflects bone density and structure by reduction analysis of ultrasound pulse intensity through the bone; SOS expresses speed of ultrasound wave through the bone and reflects bone mineral density. SOS is related to temperature, while BUA is inversely related to temperature. These correlation coefficients $(\alpha, \beta)$ are combined with BUA and SOS to obtain the BQI (BQI $=\alpha \times \operatorname{SOS}+\beta \times$ BUA) [36].

\section{Statistical analysis}

Results were expressed as mean and Standard Deviation (SD) 
Table 1: Characteristics of the study population.

\begin{tabular}{|c|c|}
\hline Number of patients & 30 \\
\hline Gender (M/F) & $13 / 17$ \\
\hline Ethnicity & 30/30 Caucasian, (1 Albanian, 1 Greek) \\
\hline Age (median, range in years) & $10.8(4.1-18)$ \\
\hline \multirow{2}{*}{ Type of PKU } & Classic $19 / 30(63 \%)$ \\
\hline Tanner stage (I, II, III, IV, V) & Mild/moderate $11 / 30(37 \%)$ \\
\hline Sapropterin therapy & $14,4,5,5,3$ \\
\hline
\end{tabular}

or median and Interquartile (IQ) range, according to variable distribution. Qualitative variables were expressed as proportions or percentages. We analyzed variable distribution with Shapiro-Wilk test and compared results using the t-test, Mann Whitney, or correlation test. Associations between qualitative variables were calculated by Fisher's exact test and $\mathrm{p}<0.05$ was considered as statistically significant. Univariate linear regression was used to evaluate the relationship between each individual outcome, and the correlation coefficients were calculated, with the indication of the range at $95 \%$ confidence interval (95\% CI).

\section{Results}

\section{Demographic and anthropometric findings}

Thirty PKU patients were included in the study. Their demographic and anthropometric characteristics are summarized in Table 1. Nineteen out of $30(63 \%)$ had a classic form of PKU (PKU guidelines), while the remaining had mild / moderate PKU. All patients were on a low-Phe diet. In three mild/moderate PKU cases, Sapropterine therapy at a dose of $10 \mathrm{mg} / \mathrm{kg} /$ day was associated. Fourteen patients (6 females) were prepubertal (Tanner stage I), while the remaining 16 ( 8 females) were in Tanner stage 2-5 (Table 1)

Table 2 summarizes the anthropometric, nutritional and biochemical profile of the two groups. Compliance with the diet was good in $72 \%$ of cases [10/14] in the prepubertal group and in $62.5 \%$
$(10 / 16]$ in the pubertal group (p-value: 0.57$)$. The caloric intake/kg was higher in the group of prepubertal children then adolescents (p-value: 0.0004) according to $\mathrm{FAO} / \mathrm{WHO} / \mathrm{UNU} 1985$ requirements. The total protein intake was also significantly higher in the group of prepubertal children than in adolescents (p-value: 0.005), due to the intake of synthetic proteins (PKU guidelines). The levels of natural proteins and Phe intake in the two groups of patients were comparable (Table 2). No statistically significant differences were found in the $\mathrm{z}$-scores of weight, height and BMI, with a non-significant trend to higher values weight $\mathrm{z}$-score in prepubertal than pubertal subjects, and height $z$-score in pubertal group then prepubertal subjects. The BMI z-score for both groups was within the normal range. The three patients who received Sapropterine treatment $(1$ child and 3 adolescents) had a natural protein intake of $0.21,0.40$ and $0.70 \mathrm{~g} / \mathrm{kg}$. All of them had a BMI in the range of overweight (BMI z-score > + 1.0 SDS).

Parameters of glucose and lipid metabolism were normal in all cases (Table 2). Although no significant difference was found, a trend toward higher values of the lipid profile parameters was observed in the prepubertal group. The mean values of $\mathrm{OH}-25$ vitamin $\mathrm{D}$ were at the lower limit of normal range in both groups.

\section{BIA parameters}

FM and PBF values were higher in the prepubertal group than in the pubertal one, reaching statistical significance for PBF (Figure 1), whereas TBW and LBM values were significantly higher in the pubertal group. According to sex, TBW values were significantly higher in prepubertal males than in females (p-value: 0.0005) (Table 3). After beginning of sexual development, higher levels of FM and $\mathrm{PBF}$ were found in females, in association with higher WHR.

\section{QUS parameters}

The QUS values showed an average $\mathrm{z}$-score BQI in the range of osteopenia in the study population (-1.4). Mean BQI in prepubertal children was lower than in adolescents, reaching statistical significance (p-value: 0.008), as well as BUA (p-value: 0.004) (Figure

Table 2: Anthropometrics, nutritional and laboratory parameters of PKU prepubertal and pubertal patients.

\begin{tabular}{|c|c|c|c|}
\hline & Prepubertal ( $n=14$ subjects) & Pubertal ( $n=16$ subjects) & p-value \\
\hline Age, median (IQR) & $9(4.45)$ & $15.2(4.6)$ & ----------. \\
\hline Type of PKU & 8 classical $6 \mathrm{mild} /$ moderate & 11 classical 5 mild $/$ moderate & NS \\
\hline Weight Z-score (mean $\pm S D$ ) & $0.50 \pm 1.24$ & $0.24 \pm 1.05$ & NS \\
\hline Height Z-score (mean $\pm \pm S D$ ) & $-0.11 \pm 1.06$ & $-0.525 \pm 1.35$ & NS \\
\hline BMI Z-score (mean $\pm S D)$ & $0.65 \pm 1.06$ & $0.60 \pm 0.87$ & NS \\
\hline Calories (kcal/kg) median (IQR) & $55.78(21.36)$ & $31.5(14)$ & 0.0004 \\
\hline Total protein intake $(\mathrm{g} / \mathrm{kg})$ median (IQR) & $1.45(0.30)$ & $1.13(0,24)$ & 0.005 \\
\hline Natural protein intake $(\mathrm{g} / \mathrm{kg}$ ) median (IQR) & $0.54(0.27)$ & $0.30(0.38)$ & NS \\
\hline Phe intake (mg/day) median (IQR) & $15.6(9.14)$ & $9.33(10.46)$ & NS \\
\hline Total cholesterol (mg/dL) (mean \pm SD) & $159.91 \pm 15.39$ & $143.47 \pm 37.37$ & 0.09 \\
\hline HDL cholesterol (mg/dL) (mean \pm SD) & $52.09 \pm 10.35$ & $49.60 \pm 15.43$ & 0.32 \\
\hline LDL cholesterol (mg/dL) (mean $\pm S D)$ & $90.55 \pm 13.74$ & $77.40 \pm 28.03$ & 0.08 \\
\hline Triglycerides (mg/dL) (mean $\pm \mathrm{SD})$ & $86.45 \pm 44.80$ & $84.29 \pm 52.57$ & 0.46 \\
\hline Fasting glucose (mg/dL) (mean $\pm S D)$ & $82.36 \pm 5.90$ & $84.47 \pm 5.89$ & 0.19 \\
\hline $25(\mathrm{OH})$-Vitamin D (ng/ml) (mean $\pm \mathrm{SD})$ & $32.58 \pm 11.22$ & $31.32 \pm 13.12$ & 0.41 \\
\hline
\end{tabular}


Table 3: Comparisons of BIA and QUS parameters according to gender.

\begin{tabular}{|c|c|c|c|c|c|c|}
\hline Variable & Prepubertal males & Prepubertal females & p-value & Pubertal males & Pubertal females & p-value \\
\hline \multicolumn{7}{|c|}{ BIA } \\
\hline FM & 12.63 & 9.53 & NS & 5.21 & 17.02 & 0.005 \\
\hline BF\% & 30.7 & 29.83 & NS & 10.9 & 23 & 0.06 \\
\hline TBW & 17.57 & 15.98 & 0.0005 & 35.3 & 38.3 & NS \\
\hline WHR & 0.8 & 0.72 & NS & 0.8 & 0.97 & 0.02 \\
\hline LBM & 12.23 & 10.88 & NS & 28.48 & 29.34 & NS \\
\hline \multicolumn{7}{|c|}{ QUS } \\
\hline BUA & 63.2 & 60.66 & NS & 79.5 & 76.04 & NS \\
\hline sos & 1501.75 & 1499.71 & NS & 1512.78 & 1503.16 & NS \\
\hline BQI & 57.88 & 56.28 & NS & 77.11 & 68.23 & NS \\
\hline Z-score & -1.7 & -1.3 & NS & -1.6 & -1.18 & NS \\
\hline
\end{tabular}

FM: Fat Mass; PBF: Percentage Of Body Fat; TBW: Total Body Water; WHR: Waist-Hip Ratio; LBM: Lean Body Mass; BUA: Broadband Ultrasound Attenuation; SOS: Speed Of Sound; BQI: Bone Quality Index

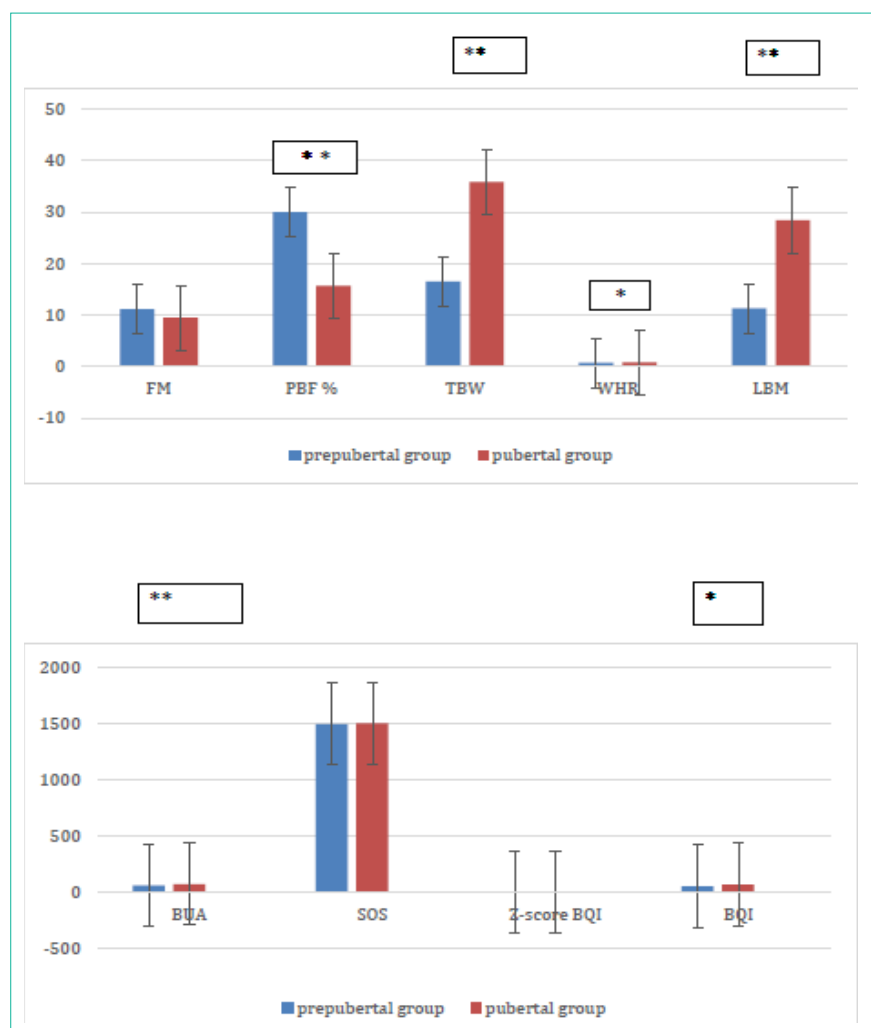

Figure 1: BIA and QUS parameters of prepubertal and pubertal PKU patients. Legend: ${ }^{*} \mathrm{p} \leq 0.05,{ }^{* *} \mathrm{p} \leq 0.01,{ }^{* * *} \mathrm{p} \leq 0.001$

FM: Fat Mass; PBF: Percentage Of Body Fat; TBW: Total Body Water WHR: Waist-Hip Ratio; LBM: Lean Body Mass; BUA: Broadband Ultrasound Attenuation; SOS: Speed of Sound; BQI: Bone Quality Index

1). A similar distribution between the two groups was observed for SOS and Z-score values.

\section{Correlations}

The BIA and QUS parameters were correlated with age, caloric intake $/ \mathrm{kg}$, protein intake $/ \mathrm{kg}$ and natural protein intake $/ \mathrm{kg}$. There was a positive correlation between age and TBW and LBM $\left(\mathrm{r}^{2} 0.78 ; \mathrm{r}^{2}\right.$ 0.51) (Figure 2). A significant correlation was also observed between caloric intake/kg and TBW (r 0.71, $\mathrm{r}^{2} 0.49$, p-value 0.0001$)$ and caloric

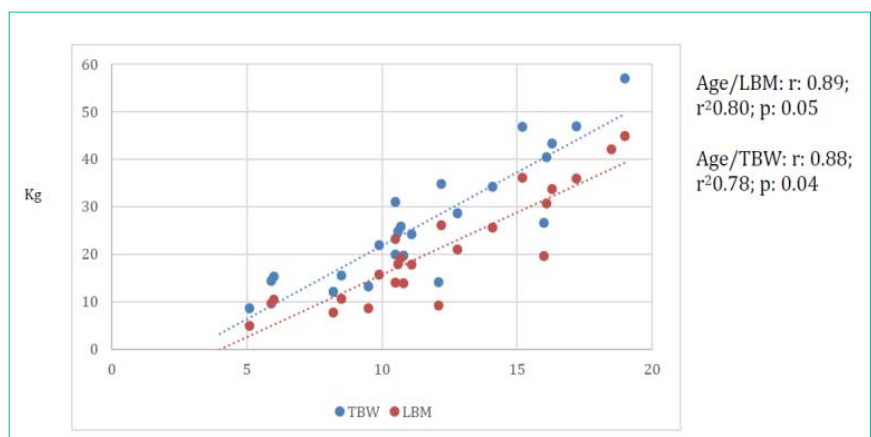

Figure 2: Positive correlation between age/LBM and age/TBW.

intake/kg and LBM (r 0.72, $\mathrm{r}^{2}$ 0.51, p-value: 0.0001). No correlation between the other parameters was detected.

\section{Discussion}

Many studies have reported on changes in BC in subjects with PKU, children and adults, and focused on the impact of gender, type of PKU, age at diagnosis and diet adherence [10,38-40]. Yet, little is known about the influence of pubertal development on their BC and bone quality. Although a role of hormonal changes linked to pubertal development on the $\mathrm{BC}$ and bone quality in subjects with PKU may be expected, it has not been specifically investigated.

In this cohort study, we compared BC and bone quality parameters between prepubertal children and adolescents with PKU. Results showed that, despite similar BMI levels, prepubertal children have a higher amount of FM than adolescent subjects, in whom the LBM is significantly higher and increases with age and caloric intake. In addition, gender matters, since FM and WHR are higher in adolescent females compared to males. Overall, bone quality was found to be sub-optimal in children and adolescents with PKU, but with a trend toward improvement with increasing age.

Our patients, either prepubertal or adolescents, have a mean $\mathrm{Z}$-score BMI in the range of normal weight. Patients on Sapropterine had a slightly higher Z-score BMI (in the range of overweight), although the number of these patients is so low (3/30) that a subgroup classification is not justifiable. There was indeed a confirmed trend to 
higher fat content in pubertal females; this finding is in keeping with data from previous studies, which highlighted that female gender was associated with increased fat percentage in adolescents with PKU [10,38-41]. Two possible explanations for this finding have been reported to be biological aspects, such as the female reproductive function and higher estrogen levels [41].

Many studies have reported strict relationship between protein intake and LBM in pubertal period $[42,43]$. After puberty, selective stimulation of whole-body protein synthesis by GH, IGF1 and androgenic hormones--all increasing in puberty-may explain increased protein gain [44]. The higher protein retention is reflected by a decreased rate of leucine oxidation in the fed state, and increased net leucine retention in pubertal than in prepubertal subjects. Leucine is a well-known stimulator of insulin secretion from pancreatic $\beta$ cells; this may result from its action as metabolic fuel and also as allosteric activator of Glutamate Dehydrogenase (GDH) [45].

Calcium absorption and retention are also positively affected by endocrine factors, particularly by gonadal steroids, GH and IGF-1 [46]. Previous studies reported an increased bone density in adolescent period, with both genders reaching peak bone acquisition, after puberty [47]. The higher protein retention linked to higher muscle mass can also partly explain the increasing bone quality observed in adolescents, as it has been demonstrated under conditions of adequate calcium intake [48]. Some studies have shown that adequate intake of calcium, phosphorus, and vitamin D is not sufficient for normal bone development in subjects with a reduced intake of natural protein which plays a more important role in BMD development in PKU patients [49]. In our study population, we found $25-\mathrm{OH}$ vitamin $\mathrm{D}$ at the lower limit of normal range in both groups, also other bone health markers were found within the normal range, although they could not be performed in all the patients and were not included in the study (data not shown). The absence of bone markers impairment is consistent with the finding that the altered BQI, particularly in prepubertal patients, was secondary to lower BUA levels, and not to SOS levels, which were comparable in the two groups. It has been reported that BUA is more related to structural parameters such as connectivity and porosity of the skeleton while SOS is more associated to bone mineral mass [29].

PKU diet is often characterized by a high amount of non-Phe proteins in form of Phe-free aminoacids mixtures [11]. In most patients, the free L-amino acids supply 52 to $80 \%$ of the total protein intake, as a number of observational studies have demonstrated that growth in PKU is adequate if the total protein intake meets or is above the general population recommendations [50-52].

Previous studies have emphasized the higher risk of insulin resistance and overweight in adult PKU patients, mostly linked to higher carbohydrate intake [53], although the higher protein retention, typical of this period can even further expose patients to the risk of metabolic syndrome.

Should the protein intake of these patients in the peripubertal period take the increased utilization of dietary proteins into account? Studies on body composition during puberty in general population show that all the main components of body composition increase [54], with males gaining greater amounts of fat free mass than females, who acquire significantly more fat mass after pubertal spurt [55] . In our PKU cohort, fat free body mass doubled up in males and exceeded the gain of fat mass in females, emphasizing a higher protein retention than the age-matched population.

Certainly, performing BIA in this period can represent a first approach to define patients at higher risk of protein retention. In addition, the evaluation of insulin levels with possible glucose load curve would allow a more complete metabolic assessment and a more precise definition of the risk.

In this study, we describe the results of the measurements of BMI, BIA, and QUS parameters as obtained from our population at followup observations. We did not perform prospective, individual serial measurements, which also could have been further informative, nor direct comparison with healthy controls. The present study could have benefit from information on levels of branched chain amino acid and markers of glucose homeostasis, which were not available to us in this first phase, but could have provided further evidences for the risk of metabolic syndrome.

A further limitation to the study could derive from the fact that physical activity was not described and included in the study. Due to the difficulty to obtain a realistic measurement of domestic physical activity, in the absence of extreme agonistic physical training and total inactivity among patients, it can be considered homogeneously mild-moderate in this group of patients.

In conclusion, pubertal development involves the chemical maturation of body tissues, regulating the amount and distribution of adipose tissue, and changes in bone mass and fat-free lean tissue mass. The optimal amount of Phe-free amino acids is undetermined and particularly when growth rate decreases, there is insufficient data to reach clear conclusions on the optimal amount in the treatment of PKU. If on one hand the high non-Phe protein intake may promote increase in bone mineral quality in adolescents, on the other hand the derived higher LBM may increase the risk for hyperinsulinism and glucose intolerance in later life. Adjusting dietary management by modulating total protein intake in the peripubertal period could result in better management of PKU patients.

\section{Author Contributions}

AT wrote the manuscript, AT and MFF made substantial contributions to study conception and design and interpretation of data; MLF, GP and DDG performed QUS and BIA analysis; LM made statistical analysis; MA revised critically the manuscript. All authors approved the final version of the manuscript.

\section{References}

1. Scriver CR, Kaufman S. Hyperphenylalaninemia: phenylalanine hydroxylase deficiency. Editors. In: Scriver CR, Beaudet AL, Sly SW, et al. The Metabolic and Molecular Bases of Inherited Disease. 8 edition. New York, NY: McGrawHill. 2001: 1667-1724.

2. Blau N, van Spronsen FJ, Levy HL. Phenylketonuria. Lancet 2010; 376: 1417-1427.

3. Acosta PB, Yannicelli S, Singh R, Mofidi S, Steiner RM, Vincentis ED, et al. Nutrient intakes and physical growth of children with phenylketonuria undergoing nutrition therapy. J Am Diet Assoc 2003; 103: 1167-1173.

4. Al Hafid N, Christodoulou J. Phenylketonuria: a review of current and future treatments. Transl Pediatr. 2015; 4: 304-317. 
5. Trefz KF, Muntau AC, Kohlscheen KM, Altevers J, Jacob C, Braun S, et al. Clinical burden of illness in patients with Phenylketonuria (PKU) and associated comorbidities - a retrospective study of German health insurance claims data Orphanet Journal of Rare Diseases. 2019; 14: 181.

6. Kanufre VC, Soares RDL, Alves MRA, Aguiar MJB, Starling ALP, Norton RC. Metabolic syndrome in children and adolescents with phenylketonuria. J Pediatr. 2015; 91: 98-103

7. Rocha JC, MacDonald A, Trefz F. Is overweight an issue in phenylketonuria? Mol Genet Metab. 2013; 110: S18-S24.

8. MacDonald A, Rocha JC, van Rijn M, Feillet F. Nutrition in phenylketonuria Mol Genet Metab. 2011; 104: S10-S18.

9. Singh RH, Rohr F, Frazier D, Cunningham A, Mofidi S, Ogata B, et al. Recommendations for the nutrition management of phenylalanine hydroxylase deficiency. Genet Med. 2014; 16: 121-131.

10. Evans M, Truby H, Boneh A. The relationship between dietary intake, growth and body composition in Phenylketonuria. Mol Genet Metab. 2017; 122: 36 42.

11. van Wegberg AMJ, MacDonald A, Ahring K, Bélanger-Quintana A, Blau N, Bosch AM, et al. The complete European guidelines on phenylketonuria: diagnosis and treatment Orphanet J Rare Dis. 2017; 12: 162

12. Rocha JC, van Spronsen FJ, Almeida MF, Ramos E, Guimaraes JT, Borges $\mathrm{N}$. Early dietary treated patients with phenylketonuria can achieve norma growth and body composition, Mol. Genet. Metab. 2013; 110: S40-S43.

13. Huemer M, Huemer C, Moslinger D, Huter D, Stockler-Ipsiroglu S. Growth and body composition in children with classical phenylketonuria: results in 34 patients and review of the literature. J Inherit Metab Dis. 2007; 30 694-699.

14. Atherton RR, Williams JE, Wells JCK, Fewtrell MS. Use of Fat Mass and Fat Free Mass Standard Deviation Scores Obtained Using Simple Measurement Methods in Healthy Children and Patients: Comparison with the Reference 4-Component Model PLoS One. 2013; 8: e62139.

15. Stefanaki C, Bacopoulou F, Peppa M. Prediabetes and adolescence-Trends, causes, effects, and screening. US Endocrinol. 2016; 12: 94-98.

16. Bray GA, Smith SR, de Jonge L, Xie H, Rood J, Martin CK, et al. Effect of dietary protein content on weight gain, energy expenditure, and body composition during overeating, JAMA. 2012; 307: 47-55.

17. Demirdas S, Coakley KE, Bisschop PH, Hollak CE, Bosch AM, Singh RH. Bone health in phenylketonuria: A systematic review and meta-analysis Orphanet J Rare Dis. 2015; 10: 17.

18. Doulgeraki A, Skarpalezou A, Theodosiadou A, Monopolis I, Schulpis K Body composition profile of young patients with phenylketonuria and mild hyperphenylalaninemia. Int J Endocrinol Metab. 2014; 12: e16061.

19. Adamczyk P, Morawiec-Knysak A, Płudowski P, Banaszak B, Karpe J, Pluskiewicz W. Bone metabolism and the muscle-bone relationship in children, adolescents and youngadults with phenylketonuria. J Bone Miner Metab. 2011; 29: 236-244.

20. de Castro MJ, de Lamas C, Sánchez-Pintos P, González-Lamuño D, Couce ML. Bone Status in Patients with Phenylketonuria: A Systematic Review. Nutrients. 2020; 12: 2154

21. Demirdas S, van Spronsen FJ, Hollak CEM, van der Lee JH, Bisschop PH, Vaz FM, et al. Micronutrients, Essential Fatty Acids and Bone Health in Phenylketonuria. Ann Nutr Metab. 2017; 70: 111-121.

22. Lubout CMA, Blanco FA, Bartosiewicz K, Feillet F, Gizewska M, Hollak C, et al. Bone mineral density is within normal range in most adult PKU patients. $J$ Inherit Metab Dis. 2020; 43: 251-258.

23. Stroupa BM, Hansenb KE, Kruegerc D, Binkleyd N, Ney DM. Sex differences in body composition and bone mineral density in phenylketonuria: A crosssectional study. Molecular Genetics and Metabolism Reports 2018; 15: 30 35.

24. Baroncelli GI, Federico G, Bertelloni S, Sodini F, De Terlizzi F, Cadoss $R$, et al. Assessment of bone quality by quantitative ultrasound of proxima phalanges of the hand and fracture rate in children and adolescents with bone and mineral disorders. Pediatr Res. 2003; 54: 125-136.

25. Christoforidis A, Printza N, Gkogka C, Siomou E, Challa A, Kazantzidou E, et al. Comparative study of quantitative ultrasonography and dual-energy X-ray absorptiometry for evaluating renal osteodystrophy in children with chronic kidney disease. J Bone Miner Metab. 2011; 29: 321-327.

26. Krieg MA, Barkmann R, Gonnelli S, Stewart A, Bauer DC, Del Rio BLet al Quantitative ultrasound in the management of osteoporosis: the 2007 ISCD Official Positions. J Clin Densitom. 2008; 11: 163-187.

27. Aceto G, D'Addato O, Messina G, Carbone V, Cavallo L, Brunetti G, et al. Bone health in children and adolescents with steroid-sensitive nephrotic syndrome assessed by DXA and QUS. Pediatr Nephrol. 2014; 29: $2147-$ 2155.

28. Tanaka NYY, Turcato MF, Nicoletti CF, Nonino CB, Martins LD, lannetta $\mathrm{O}$, et al. Effects of Short-Term Calcium Supplementation in Children and Adolescents with Phenylketonuria. Clin Densitom. 2018; 21: 48-53.

29. Lee M, Nahhas RW, Choh AC, Demerath EW, Duren DL, Chumlea WC, et al. Longitudinal changes in calcaneal quantitative ultrasound measures during childhood. Osteoporos Int. 2011; 22: 2295-2305.

30. WHO Multicentre Growth Reference Study Group. WHO Child Growth Standards based on length/height, weight and age. Acta Paediatr Suppl. 2006; 450: 76-85

31. Tanner JM, Whitehouse RH. Clinical longitudinal standards for height, weight, height velocity, weight velocity, and stages of puberty. Arch Dis Child. 1976; 51: $170-179$

32. FAO/WHO. Energy and protein requirements: Report of a joint FAO/WHO ad hoc expert committee. FAO Nutrition Meetings Report Series No. 52. WHO Technical Report Series No. 522. Rome and Geneva. 1973

33. Mysliwiec M, Walczak M, Małecka-Tendera E, Dobrzanska A, Cybulska B, Filipiak KJ, et al. Management in familial hypercholesterolaemia in children and adolescents. Position of the Lipid Expert Forum. Kardiol Pol. 2013; 71: 1099-1105.

34. Vierucci F, Del Pistoia M, Fanos M, Gori M, Carlone G, Erba P, et al. Vitamin D status and predictors of hypovitaminosis D in Italian children and adolescents: a cross-sectional study. European Journal of Pediatrics. 2013 172: $1607-1617$.

35. Stagi S, Pelosi P, Strano M, Poggi G, Manoni C, de Martino M, et al Determinants of Vitamin D Levels in Italian Children and Adolescents: A Longitudinal Evaluation of Cholecalciferol Supplementation versus the Improvement of Factors Influencing 25(OH)D Status. Int J Endocrinol. 2014; 2014: 583039.

36. Manuals and User Guides for OsteoSys SONOST 3000.

37. Assessment of fracture risk and its application to screening for postmenopausa osteoporosis. Report of a WHO Study Group. World Health Organ Tech Rep Ser. 1994; 843: 1-129.

38. Robertson LV, McStravick N, Ripley S, Weetch E, Donald S, Adam S, et al. Body mass index in adult patients with diet-treated phenylketonuria. $\mathrm{J}$ Hum Nutr Diet. 2013; 26: 1-6.

39. Burrage LC, McConnell J, Haesler R, O'Riordan MA, Sutton VR, Kerr DS, et AI High prevalence of overweight and obesity in females with phenylketonuria. Mol Genet Metab. 2012; 107: 43-48.

40. Mazzola PN, Nalin T, Castro K, van Rijn M, Derks TGJ, Ingrid TGJ, et al Analysis of body composition and nutritional status in Brazilian phenylketonuria patients. Molecular Genetics and Metabolism Reports. 2016; 6: 16-20.

41. Camatta GC, Kanufre VC, Alves MRA, Soares RDL, Norton RC, de Aguiar $M J B$, et al. Body fat percentage in adolescents with phenylketonuria and associated factors. Mol Genet Metab Rep. 2020; 23: 100595.

42. Switkowski KM, Jacques PF, Must A, Fleisch A, Oken E. Associations of protein intake in early childhood with body composition, height, and insulinlike growth factor I in mid-childhood and early adolescence. Am J ClinNutr. 2019; 109: 1154-1163.

43. van Vught AJ, Heitmann BL, Nieuwenhuizen AG, Veldhorst MA, Brummer RJ 
Westerterp-Plantenga MS. Association between dietary protein and change in body composition among children (EYHS). ClinNutr. 2009; 28: 684-688.

44. Mauras N, Rini A, Welch S, Sager B, Murphy SP. Synergistic effects of testosterone and growth hormone on protein metabolism and body composition in prepubertal boys. Metabolism. 2003; 52: 964-969.

45. Yang J, Chi Y, Burkhardt BR, Guan Y, Wolf BA. Leucine metabolism in regulation of insulin secretion from pancreatic beta cells. Nutr Rev. 2010; 68: $270-279$

46. Mauras N, Rogol AD, Haymond MW, Veldhuis JD. Sex steroids, growth hormone, insulin-like growth factor-1: neuroendocrine and metabolic regulation in puberty. Horm Res. 1996; 45: 74-80.

47. Zulfarina MS, Sharkawi AM, Aqilah-S NZS, Mokhtar SA, Nazrun SA, NainaMohamed I. Influence of Adolescents' Physical Activity on Bone Minera Acquisition: A Systematic Review Article. Iran J Public Health. 2016; 45 1545-1557.

48. Kelsey M. Mangano, Shivani Sahni, and Jane E. Kerstetter Dietary protein is beneficial to bone health under conditions of adequate calcium intake: an update on clinical research Curr Opin Clin Nutr Metab Care. 2014; 17: 69-74

49. Rizzoli R, Biver E, Bonjour JP, Coxam V, Goltzman D, Kanis JA, et al Benefits and safety of dietary protein for bone health-an expert consensus paper endorsed by the European Society for Clinical and Economical Aspects of Osteoporosis, Osteoarthritis, and Musculoskeletal Diseases and by the International Osteoporosis Foundation. Osteoporos. Int. 2018; 29: 19331948.

50. Hennermann JB, Roloff S, Gellermann J, Vollmer I, Windt E, Vetter B, et al. Chronic kidney disease in adolescent and adult patients with phenylketonuria. J Inherit Metab Dis. 2013; 36: 747-756.

51. MacDonald A. Diet and compliance in phenylketonuria. Eur J Pediatr. 2000; 159: S136-S141.

52. $\mathrm{Yi} \mathrm{SH}$, Singh $\mathrm{RH}$. Protein substitute for children and adults with phenylketonuria. Cochrane Database Syst Rev. 2015; 2015: CD004731.

53. Couce ML, Sánchez-Pintos P, Vitoria I, Castro MJD, Aldamiz-Echevarría $\mathrm{L}$, Correcher $\mathrm{P}$, et al. Carbohydrate status in patients with phenylketonuria. Orphanet J Rare Dis. 2018; 13: 103.

54. Siervogel RM, Demerath EW, Schubert C, Remsberg KE, Chumlea WC, Sun S, et al. Puberty and body composition. Horm Res. 2003; 60: 36-45.

55. Loomba-Albrecht, Lindsey A; Styne, Dennis M. Effect of puberty on body composition, Current Opinion in Endocrinology, Diabetes and Obesity: February 2009; 16: 10-15 